\title{
Bilaterally symmetrical lupus profundus with livedo reticularis as a sole cutaneous manifestation in a case of systemic lupus erythematosus
}

\author{
Haritha Thiruveedhula $^{1 *}$, Arunasree Kurapati ${ }^{1}$, Haritha Samanthula ${ }^{1}$, Madhu K. Reddy Bora ${ }^{2}$
}

\begin{abstract}
${ }^{1}$ Department of Dermatology, Venereology, and Leprosy, ${ }^{2}$ Department of Medicine, Dr. Pinnamaneni Siddhartha Institute of Medical Sciences and Research Foundation, Chinna Avutapalli, Krishna District, Andhra Pradesh, India
\end{abstract}

Received: 27 July 2020

Accepted: 02 September 2020

*Correspondence:

Dr. Haritha Thiruveedhula,

E-mail: drtharitha@gmail.com

Copyright: (C) the author(s), publisher and licensee Medip Academy. This is an open-access article distributed under the terms of the Creative Commons Attribution Non-Commercial License, which permits unrestricted non-commercial use, distribution, and reproduction in any medium, provided the original work is properly cited.

\begin{abstract}
A 31-year-old female diagnosed as a case of systemic lupus erythematosus (SLE) two years back with no cutaneous lesions, with lupus nephritis and anti-ds DNA positivity presented with the hardness of skin over the inner aspect of both thighs for four months associated with mild pain and itching. Lupus profundus was diagnosed clinically and histopathologically. She had livedo reticularis over the left leg, which can be a sign of the central nervous system's future involvement. The recent development of bilaterally symmetrical lupus profundus over thighs and livedo reticularis in a case of SLE with lupus nephritis diagnosed two years back is a rare presentation.
\end{abstract}

Keywords: Lupus profundus, Livedo reticularis, Systemic lupus erythematosus

\section{INTRODUCTION}

Lupus erythematosus profundus (LEP) is a rare variant of lupus erythematosus. It may occur as a separate disease or coexist with systemic lupus erythematosus (SLE) or discoid lupus erythematosus (DLE). Here we report a case of SLE with lupus nephritis with lupus profundus and livedo reticularis.

\section{CASE REPORT}

A 31-year-old female presented with the hardness of skin over the inner aspect of both the thighs for four months associated with mild pain and pruritus. There was no history of preceding trauma. She had joint pains. She was diagnosed as SLE, without cutaneous lesions, with lupus nephritis and anti-ds DNA positivity two years back. She had been treated with steroids and other immuno suppressants. She underwent bilateral core deco mpression of femoral head six months back for avascular necrosis, probably induced by steroids. She had been under treatment with mycophenolate mofetil (MMF) for 6 months.

Examination revealed hard, indurated, slightly pigmented, non-tender plaques with ill-defined margins, shiny, irregular surface over the medial side of both lower thighs, measuring $10 \times 10 \mathrm{~cm}$ over right and $20 \times 10 \mathrm{~cm}$ over the left side (Figure 1).

No associated specific cutaneous lesions of SLE/DLE were found. Livedo reticularis over the left leg was present (Figure 2). There was no lymphadenopathy.

Routine laboratory tests like complete blood picture, erythrocyte sedimentation rate, blood sugar, liver function tests were within normal limits. X-ray chest was normal. Connective tissue profile showed positive antinuclear antibodies with 1:320 titer by indirect immune-fluorescent assay method. Anti-double stranded DNA was positive. The rheumatoid factor was negative. Incisional biopsy from the lesion over the right thigh showed the histopathology of fat necrosis, calcification, 
perivascular infiltration of plasma cells, lymphocytes, eosinophils, and histiocytes (Figure 3). Direct immuno fluorescence was focally positive for $\operatorname{IgA}, \operatorname{IgG} \& \operatorname{IgM}$ at DEJ, and around blood vessels in the subcutaneous tissue. Clinical, histopathological, and immunological features are suggestive of Lupus profundus.

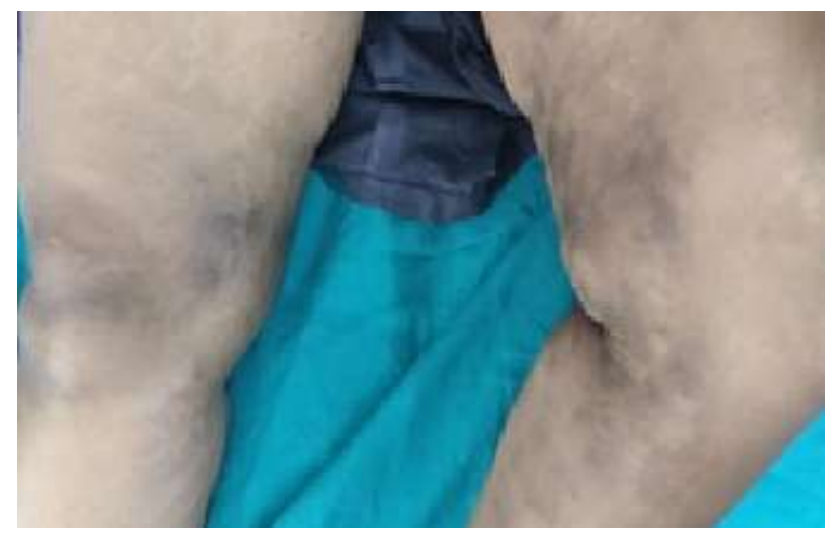

Figure 1: Hard, indurated, slightly pigmented, nontender plaques with ill-defined margins, shiny, irregular surface over the medial side of both lower thighs.

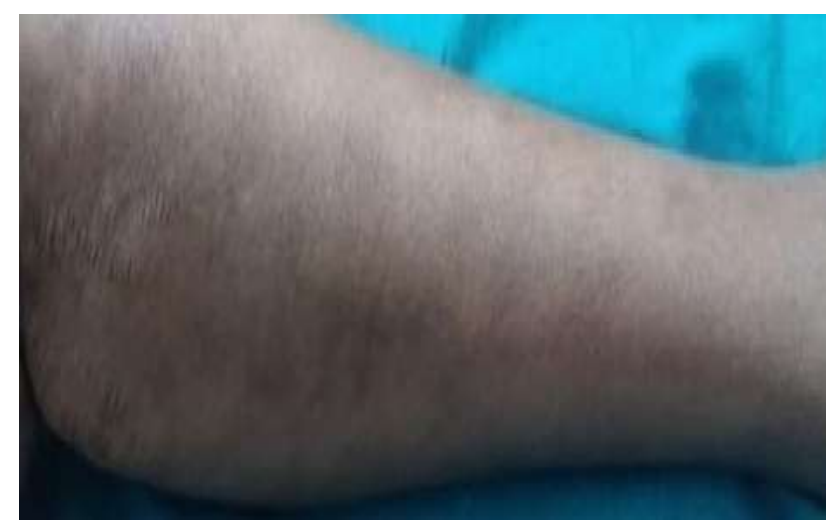

Figure 2: Livedo reticularis over the left leg can be seen.

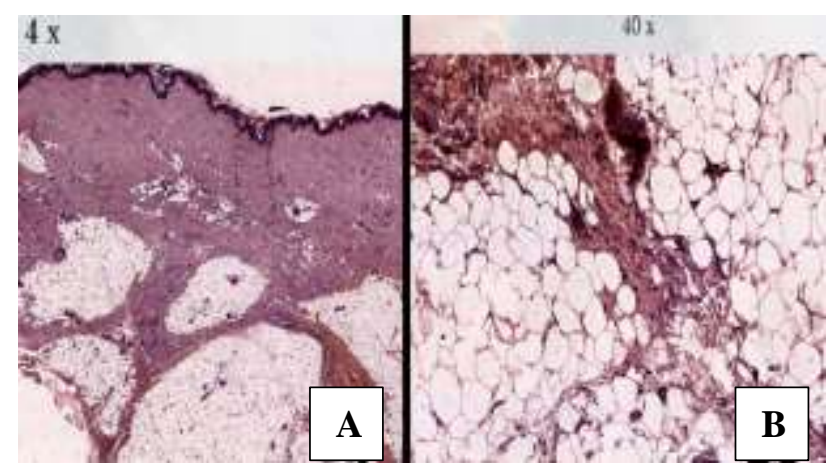

Figure 3: Fat necrosis, calcification, perivascular infiltration of plasma cells, lymphocytes, eosinophils, and histiocytes. Haematoxylin \& Eosin (H \& E) stain. (A) H \& E -4x (B) H \& E -40x.
Treatment was planned to increase the MMF dose from $500 \mathrm{mg}$ 12th hourly to $500 \mathrm{mg}$ 8th hourly and hydroxychloroquine sulphate from $200 \mathrm{mg} 24$ hourly to $200 \mathrm{mg}$ 12th hourly.

\section{DISCUSSION}

Kaposi first described this entity in 1883 as an association of subcutaneous nodules with lupus erythematosus. ${ }^{1}$ Subsequently, this finding has been recognized as lupus erythematosus (LE) profundus. ${ }^{2}$ The inflammatory reaction in LEP takes place primarily in the deep corium and the subcutaneous tissue leading to deep indurated nodules or sharply defined plaques. The overlying skin usually appears normal, but there may be erythema, atrophy, ulceration, or poikilo-dermatous or hyperkeratotic changes. ${ }^{2}$ The lesions are most frequent on cheeks, but other predilection sites are upper arms, face, hands, chest, buttocks, and thighs. The histology is that of lobular panniculitis, and the direct immunofluorescence test shows a linear pattern at the dermo-epidermal junction. The overlying epidermis may or may not show evidence of changes in typical LE. ${ }^{2}$ MMF had been continued as therapy with increased dosage as it is accepted as a treatment modality for cutaneous lupus. ${ }^{3,4,5}$ Lupus profundus used to be a specific cutaneous criterion as per American College of Rheumatology criteria 1999 and Systemic Lupus Erythematosus International Consensus Conference 2012 but in the latest 2019 EULAR/ACR criteria for SLE, this was not mentioned. ${ }^{6}$

Livedo reticularis (LR) is a cutaneous physical sign characterized by transient (or) persistent, blotchy, reddish-blue to the purple net like discoloration in a cyanotic pattern. It is a manifestation of cutaneous blood flow disturbance that may occur in various physiological and pathological states. LR may be benign as in physiological cutis marmorata of infancy or severe as in the vasculitis of LE. ${ }^{7}$

The appearance of livedo reticularis in patients with SLE may herald central nervous system involvement. In this case, the patient does not have any symptoms or signs of CNS involvement. But the patient and her family members were educated about the CNS symptoms and informed them to meet the physician as soon as they first noticed such symptoms.

Bilaterally symmetrical location of lupus profundus over both medial thighs and association of lupus profundus with livedo reticularis had not been mentioned in the literature till now as per our knowledge. ${ }^{8}$

\section{CONCLUSION}

Lupus profundus can occur as sole specific cutaneous manifestation even two years after the diagnosis of SLE, as has happened in this case. The bilaterally symmetrical presentation of lupus profundus over both medial thighs, and association of lupus profundus with livedo reticularis, 
as per our knowledge, had not been mentioned till now. As livedo reticularis can precede cerebral vasculitis, we should look for neurological symptoms and signs so that initiation of early treatment in case of positive symptoms can prevent mortality.

\section{ACKNOWLEDGEMENTS}

We are indebted to Dr. Eswar, MD, Professor of Medicine, for his constant support.

Funding: No funding sources

Conflict of interest: None declared

Ethical approval: Not required

\section{REFERENCES}

1. Suss R, Meurer M, Schirren CG, Lubke S, Ruzicka T. Lupus erythematodes profundus Kaposi-Irgang. Lupus erythematosus panniculitis [Kaposi-Irgang lupus erythematosus profundus. Lupus erythema tosus panniculitis]. Hautarz. 1994;45(1):38-41.

2. Rao TN, Ahmed K, Venkatachalam K. Lupus erythematosus profundus. Ind J Dermatol Venereol Leprol. 2010;76:448.

3. Sadlier M, Kirby B, Lally A. Mycophenolate mofetil and hydroxychloroquine: an effective treatment for recalcitrant cutaneous lupus erythematosus. J Am Acad Dermatol. 2012;66(1):160-2.
4. Kuhn A, Aberer E, Bata-Csörgő Z, Caproni M, Dreher A, Frances C et al. S2k guideline for the treatment of cutaneous lupus erythematosus - guided by the European Dermatology Forum (EDF) in cooperation with the European Academy of Dermatology and Venereology (EADV). J Eur Acad Dermatol Venereol. 2017;31(3):389-404.

5. Mok CC. Mycophenolate mofetil for non-renal manifestations of systemic lupus erythematosus: a systematic review. Scandinavi J Rheumatol. 2007;36:329-37.

6. Aringer M, Costenbader K, Daikh D, Brinks R, Mosca M, Goldman RR, et al. 2019 European League Against Rheumatism/American College of Rheumatology classification criteria for systemic lupus erythematosus. Anna Rheumat Dis. 2019;78:1151-9.

7. Sajjan VV, Lunge S, Swamy MB, Pandit AM. Livedo reticularis: A review of the literature. Indian Dermatol Online J. 2015;6(5):315-21.

8. Zhao YK, Wang F, Chen WN, Xu R, Wang Z, Jiang YW et al. Lupus Panniculitis as an Initial Manifestation of Systemic Lupus Erythematosus: A Case Report. Med (Baltimor). 2016;95(16):e3429.

Cite this article as: Thiruveedhula $\mathrm{H}$, Kurapati $\mathrm{A}$, Samanthula H, Bora MKR. Bilaterally symmetrical lupus profundus with livedo reticularis as a sole cutaneous manifestation in a case of systemic lupus erythematosus. Int J Res Dermatol. 2020;6:795-7. 